\title{
Review Article \\ Synthesis of Hyperbranched Polymer Using Slow Monomer Addition Method
}

\author{
Toshifumi Satoh \\ Division of Biotechnology and Macromolecular Chemistry, Faculty of Engineering, Hokkaido University, Sapporo 060-8628, Japan \\ Correspondence should be addressed to Toshifumi Satoh, satoh@poly-bm.eng.hokudai.ac.jp \\ Received 17 August 2011; Accepted 13 October 2011 \\ Academic Editor: Eri Yoshida \\ Copyright () 2012 Toshifumi Satoh. This is an open access article distributed under the Creative Commons Attribution License, \\ which permits unrestricted use, distribution, and reproduction in any medium, provided the original work is properly cited.
}

This paper details the synthesis of a well-defined hyperbranched polymer using a slow monomer addition method. The polymerization under slow monomer addition conditions results in a very low monomer concentration actually present in the reaction mixture, and the exclusive reaction of the monomer with the growing polyfunctional macromolecules occurs, resulting in a high molecular weight and a high degree of branching value. Thus, the slow monomer addition is a versatile and preferential method for the controlled synthesis of a well-defined hyperbranched polymer with both a high molecular weight and a high degree of branching value.

\section{Introduction}

The novel architectures of highly branched polymers, such as a dendrimer and hyperbranched polymer, have attracted much attention from the viewpoint of nanotechnology, because these polymers exhibit different characteristic features, such as a lower viscosity, higher solubility, and higher amount of terminal groups, compared with those of the corresponding linear polymers [1-15]. The dendrimers have a number of advantages, such as a monodispersity and a highly ordered structure. However, the synthesis of dendrimers has required multistep procedures of protection, deprotection, and purification. In contrast to dendrimers, the hyperbranched polymers have an irregular structure. However, the hyperbranched polymers possess properties similar to the dendrimer and can be easily synthesized via the one-pot polymerization of the $\mathrm{A}_{2}$ and $\mathrm{B}_{m}$ monomers, $\mathrm{AB}_{m}$-type monomer, and $\mathrm{AB}^{*}$ monomer (inimer), in which the A functional group of a monomer can react with the $B$ group of another monomer $[1,9,14,15]$. Therefore, the hyperbranched polymers have more extensive prospects for application and have attracted increasing interest in polymer science.

Since Kim and Webster first synthesized the hyperbranched polyphenylene by $\mathrm{AB}_{2}$-type monomers [16], numerous hyperbranched polymers have been prepared by step-growth polycondensation, self-condensing vinyl polymerization, ring-opening multibranching polymerization, self-condensing ring-opening polymerization, proton transfer polymerization, and so forth $[1,9,14,15]$. According to the experimental results and theoretical calculations, the hyperbranched polymers prepared by a one-pot reaction have a very wide polydispersity index (PDI) and the ordinary degree of branching (DB) values that limit the specification of hyperbranched polymers for advanced application, that is, the maximum $\mathrm{DB}$ value, is only about 0.5 for the $\mathrm{AB}_{2}$-type monomer or $\mathrm{AB}^{*}$ monomer and the PDI of the hyperbranched polymers is extremely broad for a high conversion $[17,18]$. In contrast, the slow monomer addition method is a highly effective way to produce the very ordered hyperbranched polymer with a controlled molecular weight, high DB, and narrow PDI [19-25]. The slow monomer addition method results in a very low monomer concentration actually present in the reaction mixture. Thus, the exclusive reaction of the monomer with the growing polyfunctional macromolecules occurs, resulting in a high molecular weight and a high DB. In the field of advanced polymer particles, it is very important to finely tune the structure of the hyperbranched polymer.

In this paper, the comprehensive study of the synthesis of hyperbranched polymers using the slow monomer addition method is described. 


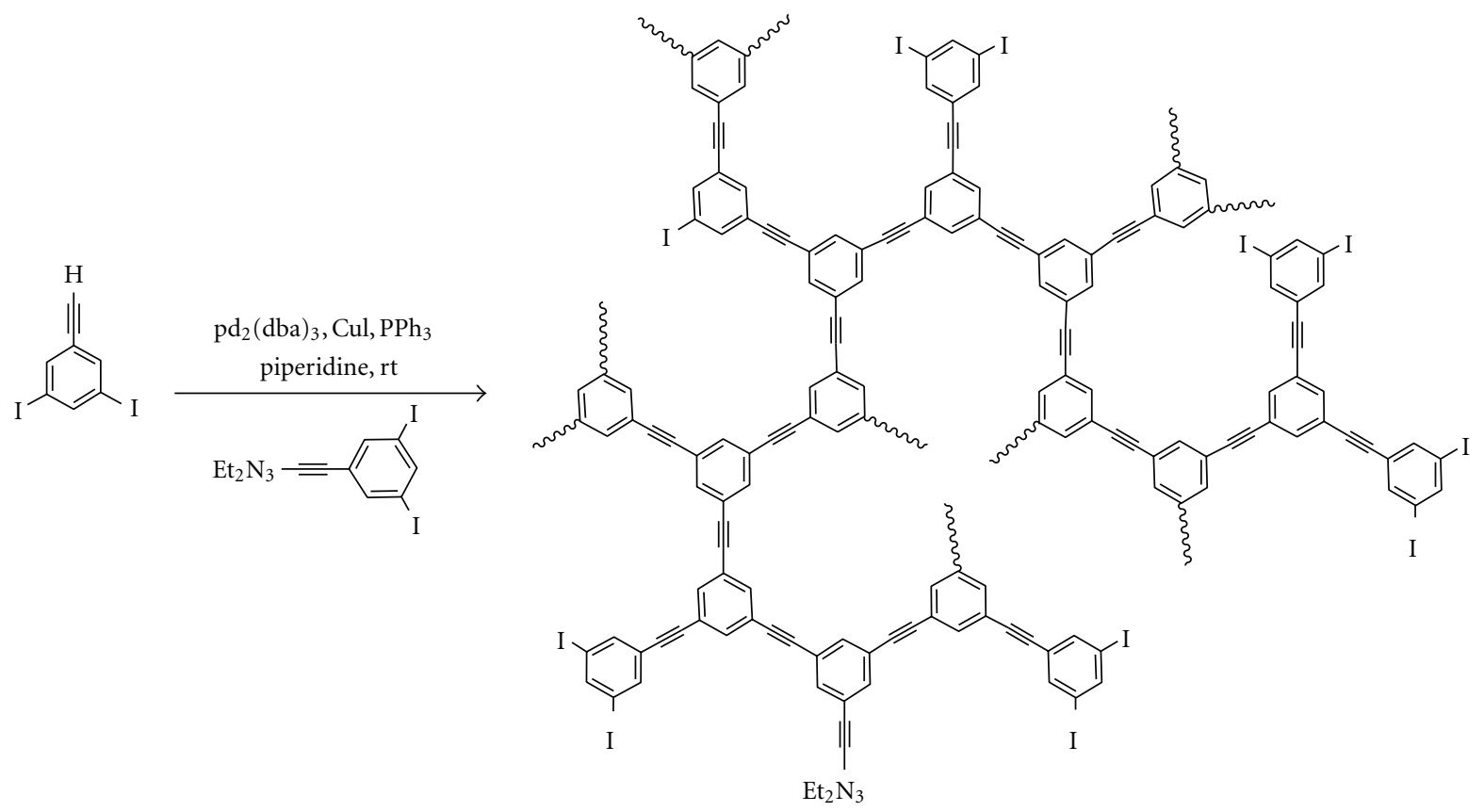

Scheme 1: Synthesis of hyperbranched polyphenylacetylene.

\section{Step-Growth Polycondensation by Slow Monomer Addition}

2.1. Synthesis of Hyperbranched Polyphenylacetylene. Bharathi and Moore first reported the synthesis of hyperbranched polyphenylacetylene by the slow monomer addition (SMA) of 3,5-diiodophenylacetylene as an $\mathrm{AB}_{2}$-type monomer, as shown in Scheme $1[26,27]$. When the slow addition of the monomer into piperidine was carried out in the presence of 1-(3,5-diiodophenyl)-3,3-diethyltriazene as a $\mathrm{B}_{2}$ core molecule and $\mathrm{Pd}_{2}$ (dibenzylideneacetone) $)_{3}$ as a catalyst, a soluble hyperbranched polymer with the weightaverage molecular weight $\left(M_{w}\right)=8220 \mathrm{~g} \cdot \mathrm{moL}^{-1}$ and PDI $=$ 1.28 (monomer: core ratio $=17.5$ ) was formed after the capping reaction. In contrast, the $M_{w}$ of the hyperbranched polymer prepared by the one-pot approach in piperidine was around $35300 \mathrm{~g} \cdot \mathrm{moL}^{-1}$ with a polydispersity near 2.4 after the capping reaction. The slow monomer addition to the catalyst solution without the core resulted in a hyperbranched polymer with a bimodal SEC profile consisting of a narrow high-molecular-weight peak and a broad tail on the low-molecular-weight side of $M_{w}=490000 \mathrm{~g} \cdot \mathrm{moL}-1$ and PDI $=33.3$.

They also achieved the control of molecular weight $\left(M_{w}=8000-90000 \mathrm{~g} \cdot \mathrm{moL}^{-1}\right)$ by varying the monomer: core ratio. The experimental results are in good qualitative agreement with computer simulations reported by Frey et al. and the theoretical work reported by Müller et al. [19-21].

2.2. Synthesis of Hyperbranched Poly(siloxysilane). Fréchet and coworkers reported the progressive SMA method to control the molecular weight and polydispersity in hyperbranched poly(siloxysilane) prepared from methylvinylbis(dimethylsiloxysilane), as shown in Scheme 2 [28]. The SMA method effectively increases the molecular weight of the final hyperbranched polymers and improves the preparation yield by reducing the occurrence of intramolecular cyclization. In addition, both the molecular weight and polydispersity could be controlled by changing the rate of addition or the amount of the monomer feed, that is, the slower the monomer addition or the higher the amount of added monomer, the higher the molecular weight $\left(M_{w}=\right.$ $8700-61000 \mathrm{~g} \cdot \mathrm{moL}^{-1}$ after precipitation) and polydispersity (2.3 to 9.2) of the resulting hyperbranched polymer. They also reported that the use of a monodisperse polyfunctional core showed a similar trend and led to a product with a higher molecular weight (a maximum $M_{w}=84000 \mathrm{~g} \cdot \mathrm{moL}^{-1}$ in $81 \%$ yield after precipitation).

2.3. Synthesis of Hyperbranched Aromatic Homo- and Copolyesters. Möck and coworkers reported the random bulk polycondensation with the SMA method leading to hyperbranched aromatic homo- and copolyesters based on 3,5bis(trimethylsiloxy)benzoyl chloride $\left(\mathrm{AB}_{2}\right.$-type monomer) and 3-(trimethylsiloxy)benzoyl chloride (AB-type monomer), as shown in Scheme 3 [29].

For the bulk homopolycondensation of the $\mathrm{AB}_{2}$ type monomer using 1,3,5-trihydroxybenzene as the $\mathrm{B}_{3}$ core molecules under the SMA conditions, the $M_{n}$ $\left(75000 \mathrm{~g} \cdot \mathrm{moL}^{-1}\right)$ of the obtained polymer was higher than that $\left(M_{n}=2900 \mathrm{~g} \cdot \mathrm{moL}^{-1}\right)$ without the SMA conditions. In addition, the DB values were significantly enhanced above the theoretical value of $0.5[17,18]$ for the onepot polycondensation to $0.61-0.66$, in agreement with the theoretical predictions $(\mathrm{DB}=0.66)[19,20]$. A remarkably 


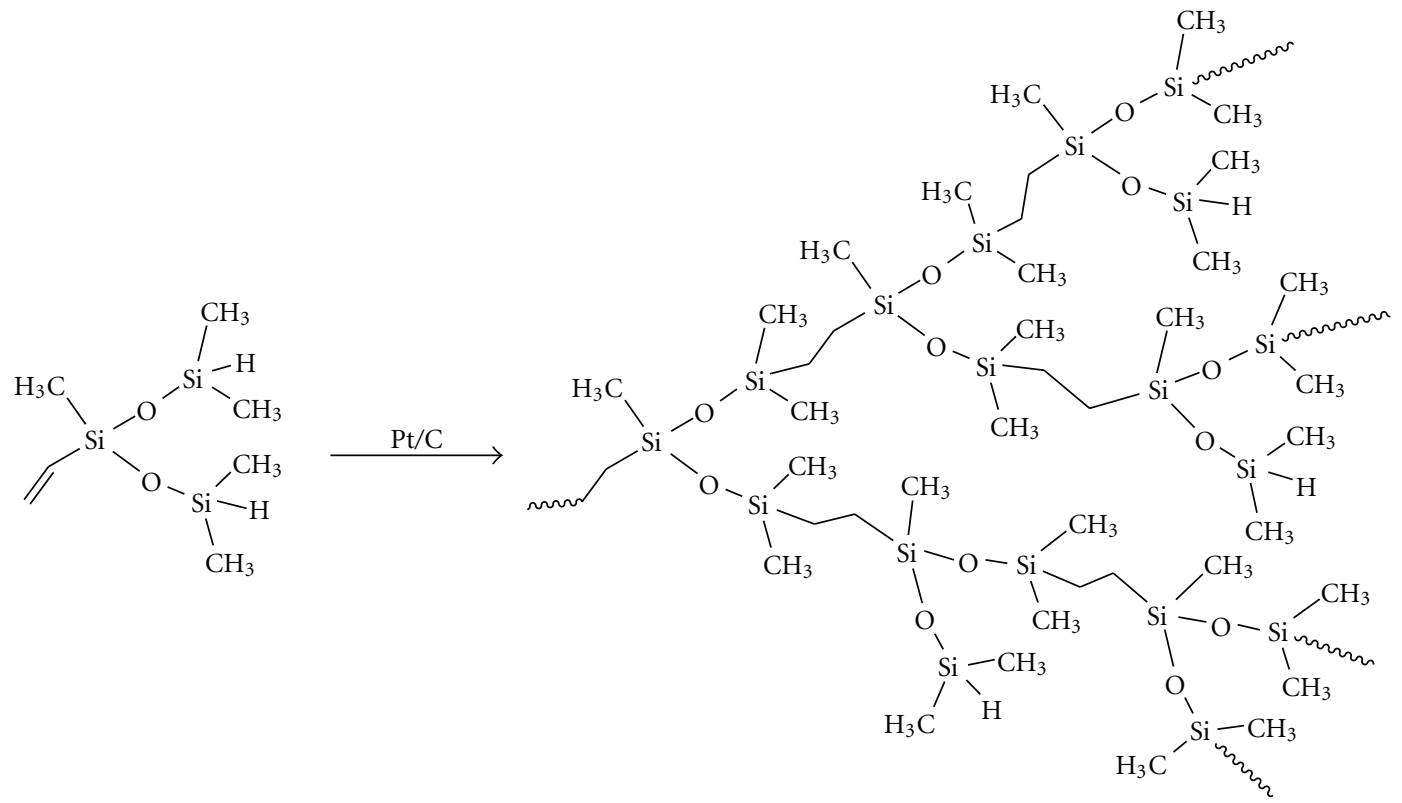

Scheme 2: Synthesis of hyperbranched poly(siloxysilane).

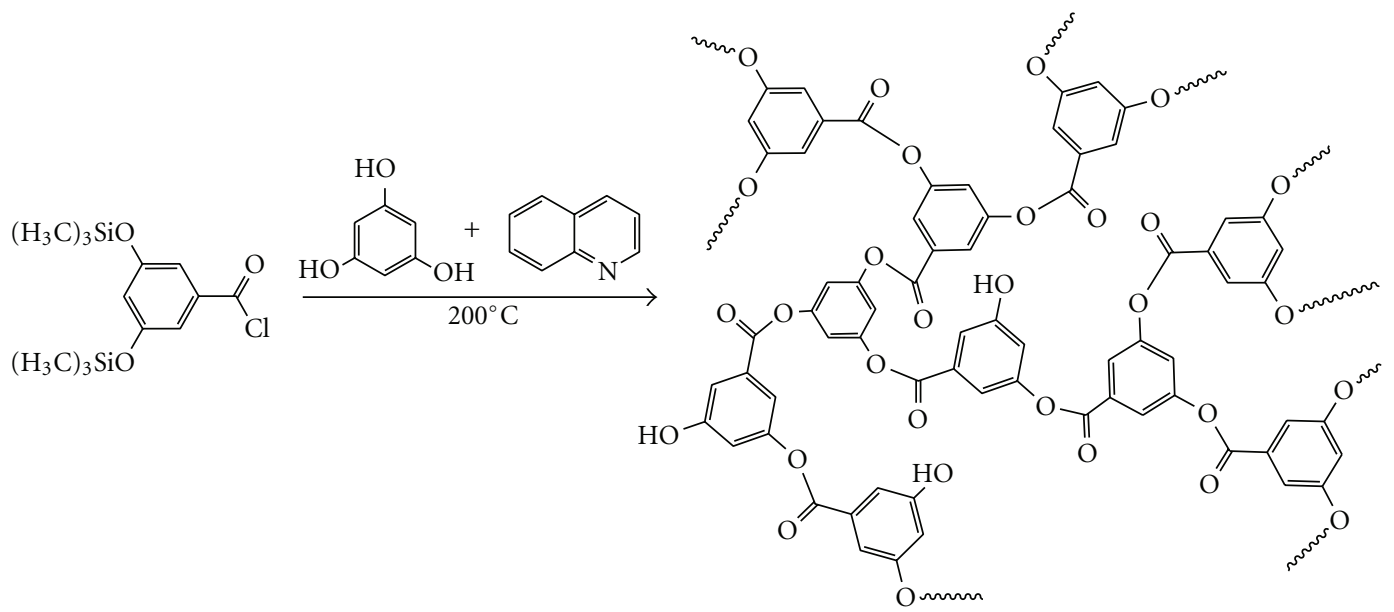

SCHeme 3: Synthesis of hyperbranched aromatic polyester.

low Mark-Houwink-Sakurada (MHS) exponent, $\alpha$, of only 0.18 in DMF (including guanidine hydrochloride) was also obtained for the hyperbranched homopolymer prepared under the SMA conditions.

For the random copolymerization using SMA conditions, the copolymer with a higher molecular weight and lower polydispersity was obtained $\left(M_{n}=83000-\right.$ $278000 \mathrm{~g} \cdot \mathrm{moL}^{-1}$, PDI $\left.=1.09-1.49\right)$, compared to the random copolymerization without SMA method $\left(M_{n}=2900\right.$ $8400 \mathrm{~g} \cdot \mathrm{moL}^{-1}$, PDI $\left.=1.37-2.15\right)$. For the copolycondensation, the variation in the molar feed ratio of the $\mathrm{AB}$ type monomer to $\mathrm{AB}_{2}$-type monomer allows varying the branching density over a broad range; that is, the $\mathrm{DB}$ values increased with the decreasing monomer feed ratio in good agreement with the DB value expected from theory $[19,20]$. The MHS exponents, $\alpha$, also clearly decreased with the increasing DB and were in the range of 0.23 to 0.55 .

\section{Ring-Opening Multibranching Polymerization by Slow Monomer Addition}

3.1. Synthesis of Hyperbranched Poly(3-ethyl-3-hydroxymethyloxetane). Magnusson and coworkers prepared hyperbranched polyethers by the cationic ring-opening multibranching polymerization of 3-ethyl-3-hydroxymethyloxetane using benzyltetramethylenesulfonium hexafluoroantimonate $\left(\mathrm{BTS}-\mathrm{SbF}_{6}\right)$ as a catalyst, as shown in Scheme 4 [30]. When 3-ethyl-3-hydroxymethyloxetane was polymerized under SMA conditions $\left(1.6 \mathrm{mmoL} \cdot \mathrm{min}^{-1}\right)$ using a trifunctional core molecule, trimethylolpropane (TMP), the polymers with $\mathrm{DB}$ values ranging from 0.15 to 0.28 , that were a lower value compared to the one-pot synthesis without the core $(\mathrm{DB}=0.40-0.41)$, were obtained. When the monomer was very slowly added to the core $\left(0.08 \mathrm{mmoL} \cdot \mathrm{min}^{-1}\right)$, the polymer with a high DB (0.40) was obtained. The 


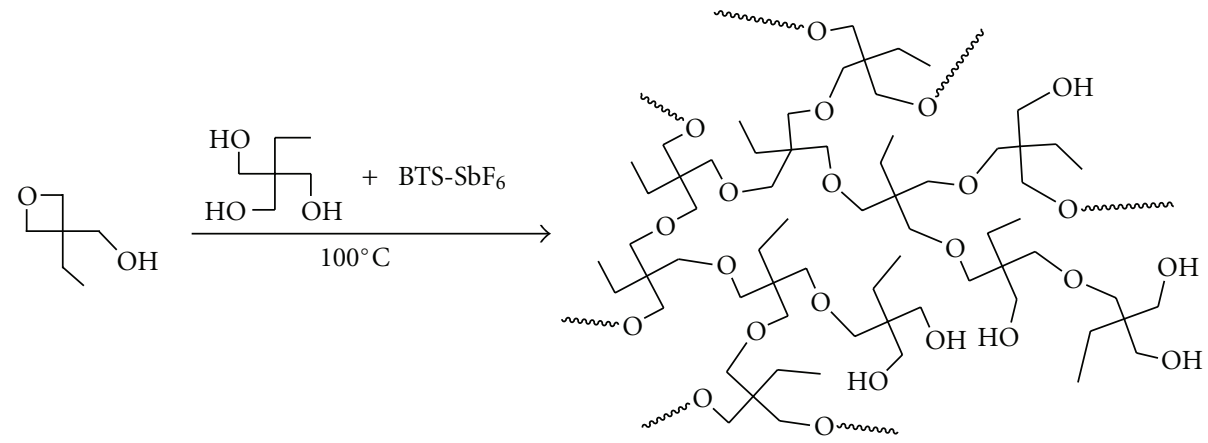

Scheme 4: Synthesis of hyperbranched poly(3-ethyl-3-hydroxymethyloxetane).

polydispersities were also slightly lower than those of the polymer from the one-pot synthesis.

They also reported the synthesis of the dumbbell-shaped triblock copolymer consisting of a linear polyethylene glycol and hyperbranched poly(3-ethyl-3-hydroxymethyloxetane) through the cationic ring-opening polymerization using the SMA method [31]. The obtained materials were of relatively low polydispersities ranging from 1.2 to 1.4 .

Smith and Mathias first reported the anionic ringopening multibranching polymerization of 3-ethyl-3-hydroxymethyloxetane using $\mathrm{NaH}$ as a strong base catalyst and TMP as a trifunctional initiator core [32]. The polymerization was carried out under SMA conditions at high temperatures $\left(>100^{\circ} \mathrm{C}\right)$ because of the high activation energy of the ring opening. The obtained polymers were of low molecular weight, and the acetone-soluble part has a higher DB value (0.48) than the acetone-insoluble one (0.20).

3.2. Synthesis of Hyperbranched Poly(2-hydroxymethyloxetane). Satoh and coworkers recently reported the cationic ring-opening multibranching polymerization of 2-hydroxymethyloxetane as a novel latent $\mathrm{AB}_{2}$-type monomer using the SMA method, as shown in Scheme 5 [33]. The polymer yield ranged from ca. 62-88\%, which increased with the increasing monomer addition time using the SMA method. The $M_{w}$ and the polydispersity of the polymer were in the range of $12,000-43,500 \mathrm{~g} \cdot \mathrm{moL}^{-1}$ and $1.60-4.53$, respectively, which also increased with the increasing monomer addition time. In contrast, the polymerization without the SMA method produced a polymer with a lower $M_{w}$ and yield, but narrower PDI. The MHS exponents, $\alpha$, in $0.2 \mathrm{M} \mathrm{NaNO}_{3}$ aq. were determined to be $0.02-0.25$, which decreased with the increasing monomer addition time. The DB value of the polymer, which was calculated by Frey's equation [18], ranged from ca. 0.50 to 0.58 , increased with the increasing monomer addition time.

Satoh and coworkers also applied the SMA method for the cationic polymerization of tetrahydrofurfuryl alcohol [33]. The $M_{w}$ values also increased with the increasing addition time, as well as the cationic ring-opening multibranching polymerization of 2-hydroxymethyloxetane, for example, $M_{w}$ was $18,200 \mathrm{~g} \cdot \mathrm{moL}^{-1}$ for the polymerization with the addition time of $20 \mathrm{~h}$, and $32,200 \mathrm{~g} \cdot \mathrm{moL}^{-1}$ for $50 \mathrm{~h}$, whereas only the oligomer was obtained without the SMA.
3.3. Synthesis of Hyperbranched Polyglycerol. In 1999, Sunder and coworkers reported the anionic ring-opening multibranching polymerization of glycidol, a latent cyclic $\mathrm{AB}_{2}-$ type monomer, under SMA conditions with TMP as a trifunctional coreinitiator, leading to polyglycerols with narrow PDIs (1.13-1.47), as shown in Scheme 6 [34]. The polymerization proceeded in a controlled manner, and the hyperbranched aliphatic polyether, possessing an $M_{n}$ in the range of 1250 to $6500 \mathrm{~g} \cdot \mathrm{moL}^{-1}$, can be prepared under the SMA conditions. The determined DB values were found to be enhanced $(0.53-0.59)$ in comparison with the value of 0.5 expected for the one-pot polymerization. The MALDI-TOF mass spectra of the obtained polymers revealed complete attachment of the hyperbranched structures to the TMP initiator and the absence of macrocyclics due to the SMA. The chiral hyperbranched polyglycerols have also been prepared in a similar manner using the enantiomerically pure glycidol [35].

Satoh and coworkers also reported the cationic ringopening multibranching polymerization of glycidol using the SMA method [33]. The polymer yield increased using the SMA method, for example, an $81.1 \%$ yield for the polymerization without the SMA and a 91.1\% yield for the polymerization with the addition time of $2.08 \mathrm{~h}$. The $M_{w}$ values $\left(9500-10100 \mathrm{~g} \cdot \mathrm{moL}^{-1}\right)$ of the polymer obtained with $\mathrm{BF}_{3} \cdot \mathrm{OEt}_{2}$ showed a small change for the addition time, though the $M_{w}$ values increased with the increasing amount of the cationic agent. The polydispersities of the resulting polymers were broad in the range of 2.06-2.11. The MHS exponents, $\alpha$, were determined to be $0.03-0.26$ in $0.2 \mathrm{M} \mathrm{NaNO}_{3}$ aq., which decreased with the increasing monomer addition time. The DB values also increased with the increasing monomer addition time, but the change was moderate, for example, the DB was 0.47 without the SMA method and 0.50 for the $6.66 \mathrm{~h}$ addition time.

A further important improvement in the ring-opening multibranching polymerization of glycidol was reported in 2006 by Kainthan and coworkers [36]. They synthesized very high molecular weight (up to $M_{n}=670000 \mathrm{~g} \cdot \mathrm{moL}{ }^{-1}$ ) and narrow polydispersed (1.1-1.4) hyperbranched polyglycerols by the anionic ring-opening multibranching polymerization of glycidol in dioxane as an emulsifying agent using the SMA method. The isolated polymer yields were between 80 and $90 \%$, and the MHS exponents, $\alpha$, were in the range 


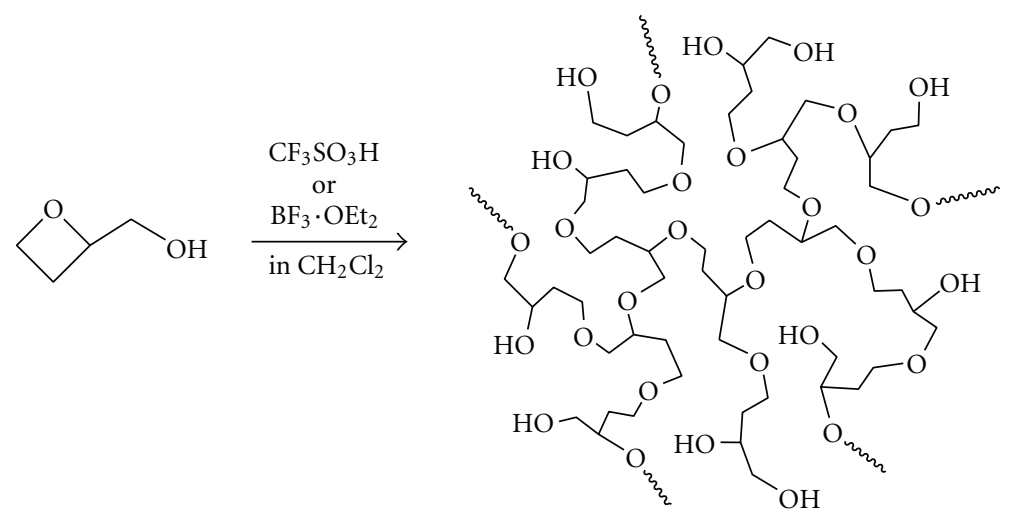

Scheme 5: Synthesis of hyperbranched poly(2-hydroxymethyloxetane).
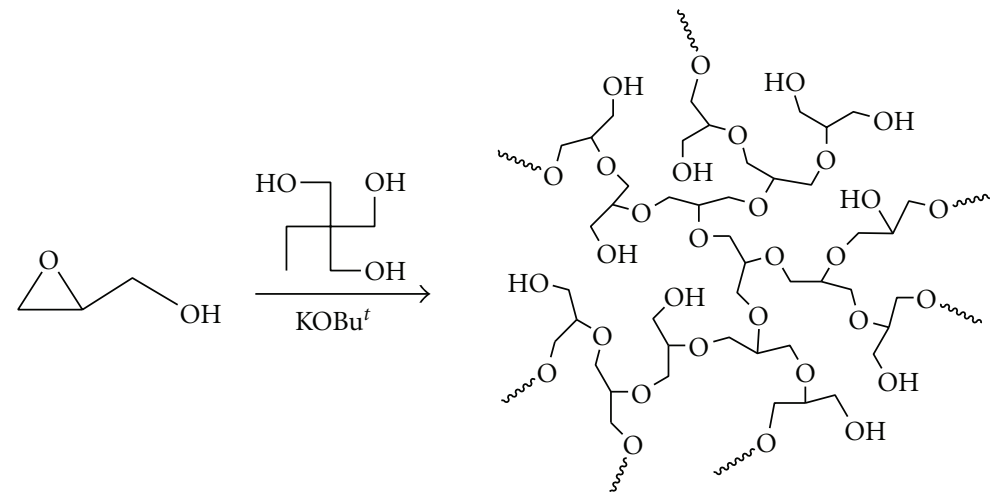

ScHeme 6: Synthesis of hyperbranched polyglycerol from glycidol.

of $0.31-0.34$. In contrast, broader polydispersities with lowmolecular-weight fractions were obtained when the more polar diglyme was used as the emulsifying agent.

In past year, a facile two-step approach via lowmolecular-weight polyglycerol macroinitiators $\left(M_{n}=500\right.$ and $\left.1000 \mathrm{~g} \cdot \mathrm{moL}^{-1}\right)$ using the SMA method was developed by Wilms and coworkers for preparing a hyperbranched polyglycerol with a controlled molecular weight [37]. The polyfunctionality of the macroinitiator affords a higher concentration of alkoxide sites even at an elevated degree of polymerization and thus permits the preparation of hyperbranched polyglycerols up to $M_{n}=24000 \mathrm{~g} \cdot \mathrm{moL}^{-1}$ under controlled SMA conditions. The polydispersities of the obtained samples were in the range of 1.3 to 1.8 , and the DB values were obtained in the range of 0.60 to 0.63 .

Rokichi and coworkers recently reported the synthesis of hyperbranched polyglycerol by the anionic ringopening multibranching polymerization of the environmentally benign monomer, glycerol carbonate, as shown in Scheme 7 [38]. The polymerization using the SMA method and partially deprotonated TMP as an initiator led to the formation of the hyperbranched polyglycerol upon $\mathrm{CO}_{2}$ liberation. The obtained polymers were of low molecular weight, and the polydispersities ranged between 1.2 and 1.3. The polymerization with the alkoxide proceeded through two reaction pathways in which attack at the carbonyl or alkyl carbon atoms of the cyclic carbonate group takes place. Although the chemical structure of the polymer was very similar to that from glycidol, the polymer contained the terminal 1,3-dihydroxy unit, which was the result of an intramolecular rearrangement. In addition, the MALDITOF mass analysis confirmed the relatively small amount of macrocyclic units in the polymer.

The high concentration of hydroxy groups on the hyperbranched polyglycerol, which can be easily transformed into other functional groups, enables the use of new materials for nanotechnology and biomedical applications such as drug carriers, molecular labels or probe moieties, and hydrogels.

3.4. Synthesis of Hyperbranched Glycopolymer. Tamaki and coworkers reported the cationic ring-opening multibranching polymerization of 5,6-anhydro-1,2-O-isopropylidene$\alpha$-D-glucofuranose as a latent cyclic $\mathrm{AB}_{2}$-type monomer using $\mathrm{BF}_{3} \cdot \mathrm{OEt}_{2}$ as an initiator in order to synthesize a novel hyperbranched glycopolymer, as shown in Scheme 8 [39]. The cationic polymerization without the SMA method produced the glycopolymer with $M_{w}=15000 \mathrm{~g} \cdot \mathrm{moL}{ }^{-1}$ and $\mathrm{PDI}=1.45$. On the other hand, the cationic polymerization with the SMA method is a facile method leading to hyperbranched glycopolymers with high molecular weights and highly branched structures; that is, the $M_{w}$ values (37000$\left.122400 \mathrm{~g} \cdot \mathrm{moL}^{-1}\right)$ increased with the increasing monomer 


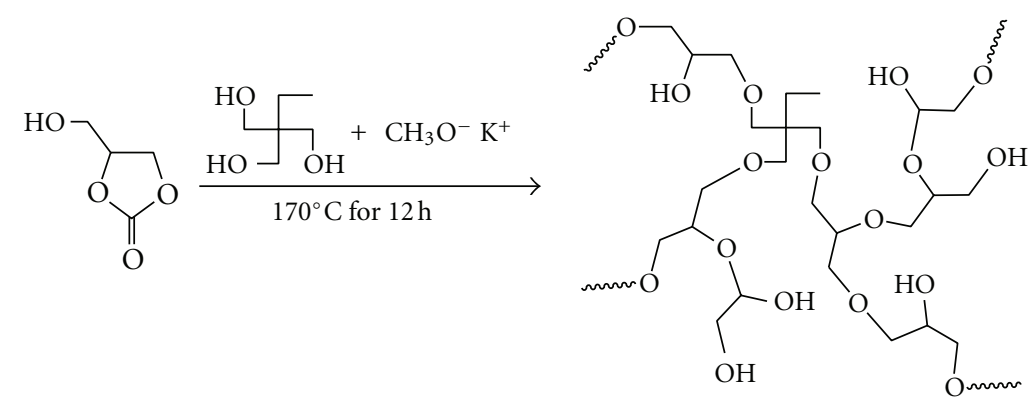

Scheme 7: Synthesis of hyperbranched polyglycerol from glycerol carbonate.

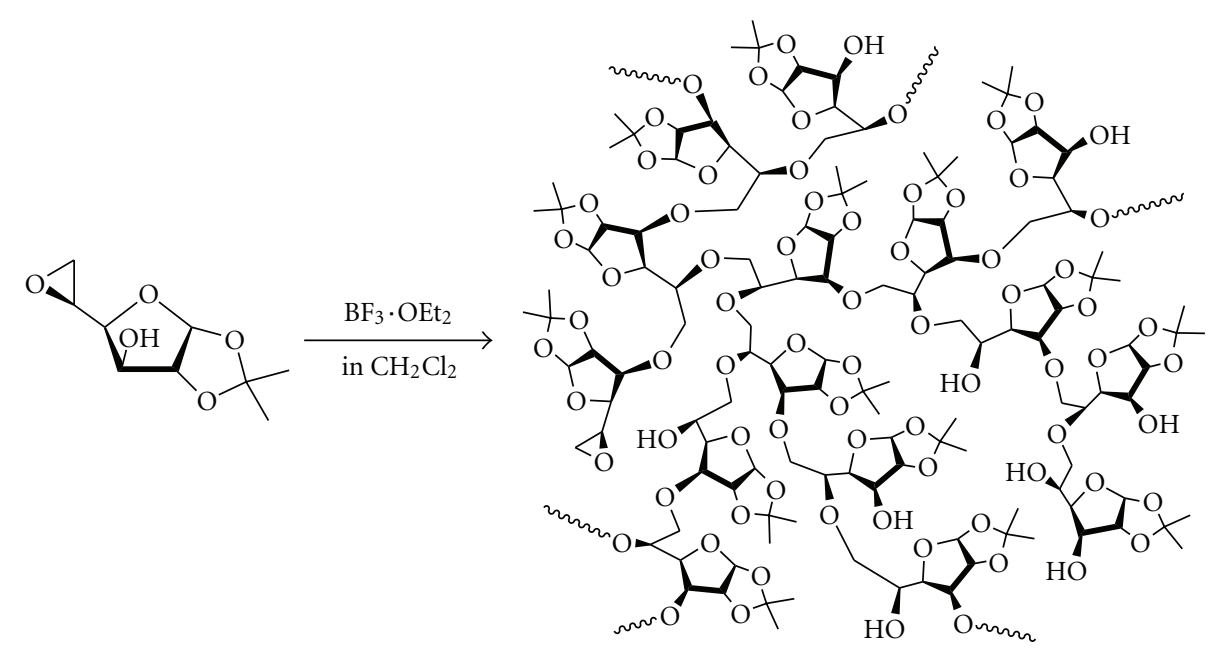

SCHEME 8: Synthesis of hyperbranched glycopolymer.

addition time and the MHS exponents, $\alpha$, were calculated to be 0.08-0.09 in 0.2 $\mathrm{M} \mathrm{NaNO}_{3}$ aq., suggesting that the resulting polymers have a highly branched spherical structure. The polydispersities were found to be in the relatively narrow range of 1.19-1.70.

The resulting polymer is a novel hyperbranched glycopolymer arranged with numerous sugar units on the peripheries of the polymer. Thus, a water-soluble hyperbranched 5,6-glucan synthesized by the hydrolysis of the hyperbranched glycopolymer has a high reducing ability derived from the glycol-cluster effect of the reducing D-glucose units; that is, the "reducing sugar ball" effectively acts as a sugar-based reductant. Such a hyperbranched glycopolymer with numerous reducing sugar units can be expected to be useful in a wide variety of fields such as biochemical and medicinal applications, for examples, a biocompatible reductant, antioxidant, and a part of the carrier for a drug delivery system, and so forth.

\section{Conclusion}

This paper describes that the slow monomer addition is a versatile and preferential method for the controlled synthesis of a well-defined hyperbranched polymer with both a high molecular weight and a high degree of branching value.
The slow monomer addition method also reduced the undesired intramolecular cyclization reactions during the polymerization. Because the hyperbranched polymers have many characteristic features and their numerous terminal units can be easily converted into various functional groups leading to novel advanced polymer particles, the welldefined hyperbranched polymers prepared using the slow monomer addition method can be expected to be useful in a wide variety of industrial and research fields, for example, molecular capsules as a carrier for a drug delivery system [40-44], a nanoreactor [45], a mixture separator [46], a viscosity modifier, a cross-linker for preparing functional gels, and so forth.

\section{Acknowledgments}

The author acknowledges the contributions of T. Kakuchi, R. Sakai, M. Tamaki, Y. Kitajyo, K. Mori, S. Nakabayashi, T. Taguchi, H. Misaka, and N. T. Hoai.

\section{References}

[1] J. M. J. Frechet, "Functional polymers and dendrimers: reactivity, molecular architecture, and interfacial energy," Science, vol. 263, no. 5154, pp. 1710-1715, 1994. 
[2] C. J. Hawker and W. Devonport, "Design, synthesis, and properties of dendritic macromolecules," ACS Symposium Series, vol. 624, pp. 186-196, 1996.

[3] F. Zeng and S. C. Zimmerman, "Dendrimers in supramolecular chemistry: from molecular recognition to self-assembly," Chemical Reviews, vol. 97, no. 5, pp. 1681-1712, 1997.

[4] K. Uhrich, "Hyperbranched polymers for drug delivery," Trends in Polymer Science, vol. 5, pp. 388-393, 1997.

[5] O. A. Matthews, A. N. Shipway, and J. F. Stoddart, "Dendrimers-branching out from curiosities into new technologies," Progress in Polymer Science, vol. 23, no. 1, pp. 1-56, 1998.

[6] A. Huit, M. Johansson, and E. Malmström, "Hyperbranched polymers," Advances in Polymer Science, vol. 143, pp. 1-34, 1999.

[7] F. Vogtle, S. Gestermann, R. Hesse, H. Schwierz, and B. Windisch, "Functional dendrimers," Progress in Polymer Science, vol. 25, no. 7, pp. 987-1041, 2000.

[8] N. Hadjichristidis, M. Pitsikalis, S. Pispas, and H. Iatrou, "Polymers with complex architecture by living anionic polymerization," Chemical Reviews, vol. 101, no. 12, pp. 37473792, 2001.

[9] M. Jikei and M. A. Kakimoto, "Hyperbranched polymers: a promising new class of materials," Progress in Polymer Science, vol. 26, no. 8, pp. 1233-1285, 2001.

[10] H. Frey and R. Haag, "Dendritic polyglycerol: a new versatile biocompatible material," Reviews in Molecular Biotechnology, vol. 90, no. 3-4, pp. 257-267, 2002.

[11] C. Gao and D. Yan, "Hyperbranched polymers: from synthesis to applications," Progress in Polymer Science, vol. 29, no. 3, pp. 183-275, 2004.

[12] B. D. Mather, K. Viswanathan, K. M. Miller, and T. E. Long, "Michael addition reactions in macromolecular design for emerging technologies," Progress in Polymer Science, vol. 31, no. 5, pp. 487-531, 2006.

[13] T. Satoh and T. Kakuchi, "Synthesis of hyperbranched carbohydrate polymers by ring-opening multibranching polymerization of anhydro sugar," Macromolecular Bioscience, vol. 7, no. 8, pp. 999-1009, 2007.

[14] S. Peleshanko and V. V. Tsukruk, "The architectures and surface behavior of highly branched molecules," Progress in Polymer Science, vol. 33, no. 5, pp. 523-580, 2008.

[15] B. I. Voit and A. Lederer, "Hyperbranched and highly branched polymer architectures-synthetic strategies and major characterization aspects," Chemical Reviews, vol. 109, no. 11, pp. 5924-5973, 2009.

[16] Y. H. Kim and O. W. Webster, "Water-soluble hyperbranched polyphenylene: a unimolecular micelle?" Journal of the American Chemical Society, vol. 112, no. 11, pp. 4592-4593, 1990.

[17] C. J. Hawker, R. Lee, and J. M. J. Fréchet, "One-step synthesis of hyperbranched dendritic polyesters," Journal of the American Chemical Society, vol. 113, no. 12, pp. 4583-4588, 1991.

[18] D. Halter, A. Burgath, and H. Frey, "Degree of branching in hyperbranched polymers," Acta Polymerica, vol. 48, no. 1-2, pp. 30-35, 1997.

[19] D. Halter and H. Frey, "Degree of branching in hyperbranched polymers," Acta Polymerica, vol. 48, no. 8, pp. 298-309, 1997.

[20] R. Hanselmann, D. Hölter, and H. Frey, "Hyperbranched polymers prepared via the core-dilution/slow addition technique: computer simulation of molecular weight distribution and degree of branching," Macromolecules, vol. 31, no. 12, pp. 3790-3801, 1998.
[21] W. Radke, G. Litvinenko, and A. H. E. Müller, "Effect of core-forming molecules on molecular weight distribution and degree of branching in the synthesis of hyperbranched polymers," Macromolecules, vol. 31, no. 2, pp. 239-248, 1998.

[22] G. I. Litvinenko and A. H. E. Müller, "Molecular weight averages and degree of branching in self-condensing vinyl copolymerization in the presence of multifunctional initiators," Macromolecules, vol. 35, no. 12, pp. 4577-4583, 2002.

[23] K. C. Cheng, T. H. Chuang, J. S. Chang, W. Guo, and W. F. Su, "Effect of feed rate on structure of hyperbranched polymers formed by self-condensing vinyl polymerization in semibatch reactor," Macromolecules, vol. 38, no. 20, pp. 8252-8257, 2005.

[24] Z. P. Zhou, Z. W. Jia, and D. Y. Yan, "Effect of slow monomer addition on molecular parameters of hyperbranched polymers synthesized in the presence of multifunctional core molecules," Science China Chemistry, vol. 53, no. 4, pp. 891$897,2010$.

[25] L. Wang, X. He, and Y. Chen, "Diffusion-limited hyperbranched polymers with substitution effect," The Journal of Chemical Physics, vol. 134, no. 10, pp. 104901-104909, 2011.

[26] P. Bharathi and J. S. Moore, "Controlled synthesis of hyperbranched polymers by slow monomer addition to a core," Macromolecules, vol. 33, no. 9, pp. 3212-3218, 2000.

[27] P. Bharathi and J. S. Moore, "Solid-supported hyperbranched polymerization: evidence for self-limited growth," Journal of the American Chemical Society, vol. 119, no. 14, pp. 3391-3392, 1997.

[28] C. Gong, J. Miravet, and J. M. J. Fréchet, "Intramolecular cyclization in the polymerization of $\mathrm{ABx}$ monomers: approaches to the control of molecular weight and polydispersity in hyperbranched poly(siloxysilane)," Journal of Polymer Science, Part A, vol. 37, no. 16, pp. 3193-3201, 1999.

[29] A. Möck, A. Burgath, R. Hanselmann, and H. Frey, "Synthesis of hyperbranched aromatic homo- and copolyesters via the slow monomer addition method," Macromolecules, vol. 34, no. 22, pp. 7692-7698, 2001.

[30] H. Magnusson, E. Malmström, and A. Hult, "Influence of reaction conditions on degree of branching in hyperbranched aliphatic polyethers from 3-ethyl-3-(hydroxymethyl)oxetane," Macromolecules, vol. 34, no. 17, pp. 5786-5791, 2001.

[31] M. Rahm, R. Westlund, C. Eldsäter, and E. Malmström, "Triblock copolymers of polyethylene glycol and hyperbranched poly-3-ethyl-3-(hydroxymethyl)oxetane through cationic ring opening polymerization," Journal of Polymer Science, Part A, vol. 47, no. 22, pp. 6191-6200, 2009.

[32] T. J. Smith and L. J. Mathias, "Hyperbranched poly(3-ethyl-3hydroxymethyloxetane) via anionic polymerization," Polymer, vol. 43, no. 26, pp. 7275-7278, 2002.

[33] T. Satoh, M. Tamaki, T. Taguchi et al., "Synthesis of novel hyperbranched polymer through cationic ring-opening multibranching polymerization of 2-hydroxymethyloxetane," Journal of Polymer Science, Part A, vol. 49, no. 11, pp. 2353-2365, 2011.

[34] A. Sunder, R. Hanselmann, H. Frey, and R. Mülhaupt, "Controlled synthesis of hyperbranched polyglycerols by ringopening multibranching polymerization," Macromolecules, vol. 32, no. 13, pp. 4240-4246, 1999.

[35] A. Sunder, R. Mülhaupt, R. Haag, and H. Frey, "Chiral hyperbranched dendron analogues," Macromolecules, vol. 33, no. 2, pp. 253-254, 2000.

[36] R. K. Kainthan, E. B. Muliawan, S. G. Hatzikiriakos, and D. E. Brooks, "Synthesis, characterization, and viscoelastic properties of high molecular weight hyperbranched polyglycerols," Macromolecules, vol. 39, no. 22, pp. 7708-7717, 2006. 
[37] D. Wilms, F. Wurm, J. Nieberle, P. Böhm, U. Kemmer-Jonas, and H. Frey, "Hyperbranched polyglycerols with elevated molecular weights: a facile two-step synthesis protocol based on polyglycerol Macroinitiators," Macromolecules, vol. 42, no. 9, pp. 3230-3236, 2009.

[38] G. Rokicki, P. Rakoczy, P. Parzuchowski, and M. Sobiecki, "Hyperbranched aliphatic polyethers obtained from environmentally benign monomer: glycerol carbonate," Green Chemistry, vol. 7, no. 7, pp. 529-539, 2005.

[39] M. Tamaki, T. Taguchi, S. Nakabayashi et al., "Hyperbranched 5,6-glucan as reducing sugar ball," Polymer Chemistry, vol. 1, no. 1, pp. 82-92, 2010.

[40] R. K. Kainthan, C. Mugabe, H. M. Burt, and D. E. Brooks, "Unimolecular micelles based on hydrophobically derivatized hyperbranched polyglycerols: ligand binding properties," Biomacromolecules, vol. 9, no. 3, pp. 886-895, 2008.

[41] T. Satoh, M. Tamaki, Y. Kitajyo et al., "Synthesis of unimolecular reversed micelle consisting of a poly(L-lactide) shell and hyperbranched D-mannan core," Journal of Polymer Science, Part A, vol. 44, no. 1, pp. 406-413, 2006.

[42] Y. Kitajyo, T. Imai, Y. Sakai et al., "Encapsulation-release property of amphiphilic hyperbranched d-glucan as a unimolecular reverse micelle," Polymer, vol. 48, no. 5, pp. 12371244, 2007.

[43] Y. Kitajyo, Y. Nawa, M. Tamaki et al., "A unimolecular nanocapsule: encapsulation property of amphiphilic polymer based on hyperbranched polythreitol," Polymer, vol. 48, no. 16, pp. 4683-4690, 2007.

[44] T. Satoh, "Unimolecular micelles based on hyperbranched polycarbohydrate cores," Soft Matter, vol. 5, no. 10, pp. 1972 1982, 2009.

[45] K. R. Kumar and D. E. Brooks, "Comparison of hyperbranched and linear polyglycidol unimolecular reverse micelles as nanoreactors and nanocapsules," Macromolecular Rapid Communications, vol. 26, no. 3, pp. 155-159, 2005.

[46] T. Satoh, Y. Kitajyo, R. Sakai et al., "Size-selective encapsulation property of unimolecular reverse micelle consisting of hyperbranched D-glucan core and L-leucine ethyl ether shell," Macromolecular Symposia, vol. 279, no. 1, pp. 145-150, 2009. 

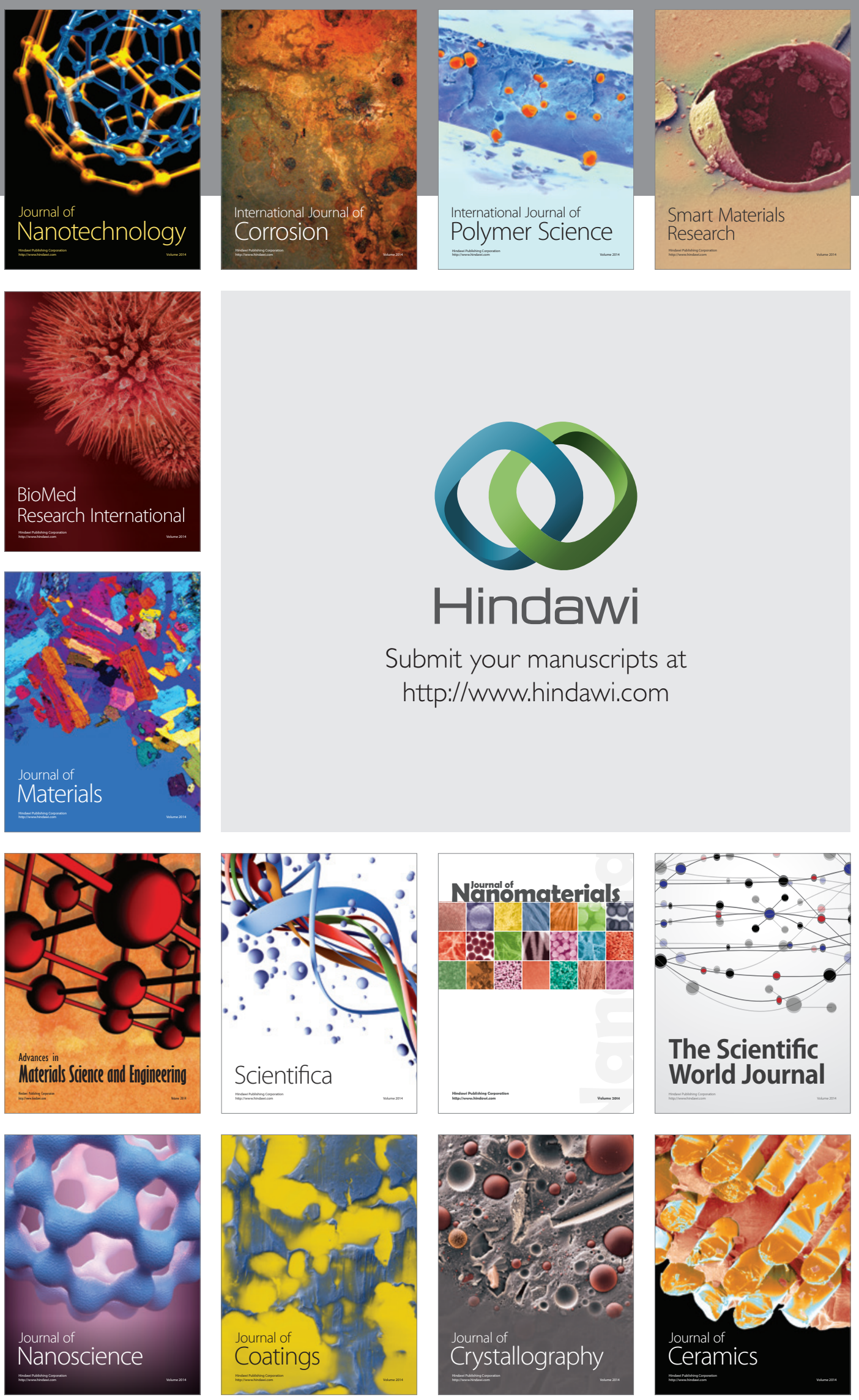

The Scientific World Journal

Submit your manuscripts at

http://www.hindawi.com

\section{World Journal}

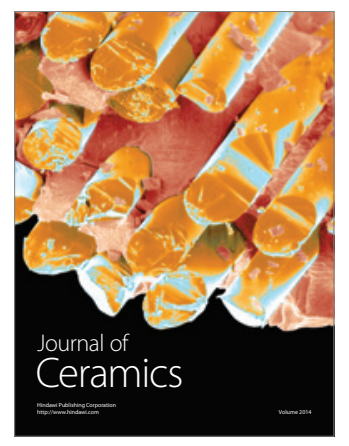

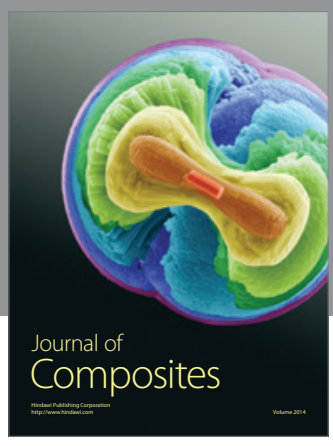
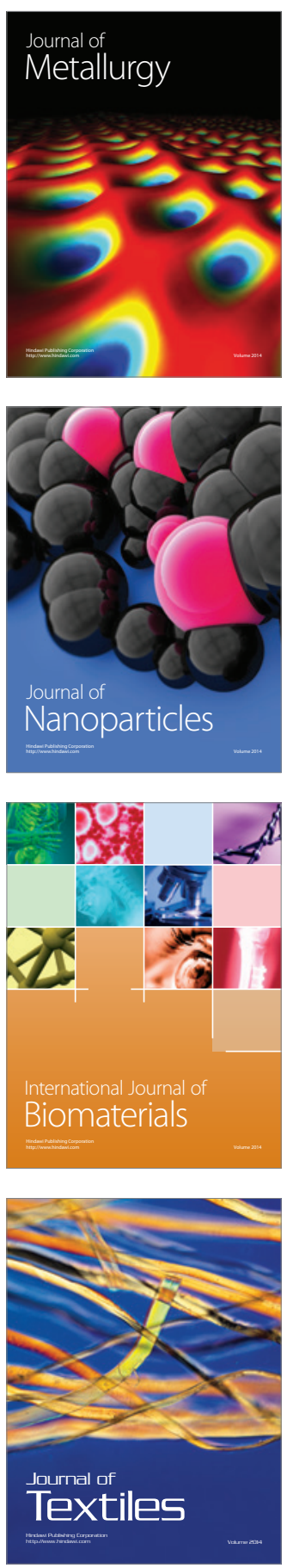